\title{
Experimental Myocardial Infarction
}

\author{
IV. REDUCTION OF LEFT VENTRICULAR COMPLIANCE \\ IN THE HEALING PHASE
}

\author{
William B. Hood, Jr., Jesus A. Bianco, Raj Kumar, and \\ Richard B. Whiting \\ From the Thorndike Memorial Laboratory, Second and Fourth (Harvard) \\ Medical Services, Boston City Hospital, the Department of Medicine, Harvard \\ Medical School, and the Department of Nutrition, Harvard School of Public \\ Health, Boston, Massachusetts 02118
}

\begin{abstract}
A в S T R A C T Compliance of the infarcted left ventricle was studied in dogs 3-5 days after occlusion of the left anterior descending coronary artery. Compliance was assessed from postmortem pressure-volume curves and from pressure-length measurements (mercury-in-silastic segment length gauges) made both in vivo and postmortem. Postmortem pressure-volume curves showed reduced compliance compared to sham-operated animals. Postmortem pressure-length curves of infarcted and adjacent normal myocardium indicated that the diminished total compliance could be attributed to an increase in stiffness of the infarcted area. This was confirmed by in vivo end-diastolic pressure-length changes produced by transient aortic occlusion. The infarcted area was akinetic, showing neither contraction nor aneurysmal bulging. In addition, anesthetized dogs with infarcts, when compared with sham-operated animals, had similar left ventricular end-diastolic volumes (indicator dilution method), but higher left ventricular enddiastolic pressures. Taken with previous observations, which show that systolic aneurysmal bulging is uniformly present at the onset of ischemia, these results indicate that stiffening of the ischemic myocardium occurs during the first 5 days after infarction, and show that elevation of left ventricular filling pressure does not necessarily signify ventricular dilatation. The results also suggest a mechanism whereby ventricular performance may improve during recovery from acute myocardial infarction.
\end{abstract}

Received for publication 8 August 1969 and in revised form 14 January 1970.

\section{INTRODUCTION}

Compromise of left ventricular performance after acute myocardial infarction has been demonstrated in both experimental (1-4) and clinical (5-8) studies. In experimental studies this impairment in ventricular function has been positively correlated with the size of the infarct measured postmortem, suggesting that the defect is directly due to loss of functioning myocardium $(3,4)$, or to systolic bulging in the area of infarction $(9,10)$, or to both. It has furthermore been demonstrated that the acute depression in ventricular function after experimental canine myocardial infarction shows considerable improvement over the 1st week after infarction (11). This finding of time-dependent improvement of ventricular function after infarction has not yet been adequately explained. However, one possible mechanism would be a decrease in compliance of the infarcted muscle, which would prevent bulging, sequestration of blood, and reduction of effective stroke volume during the systolic phase of the cardiac cycle. Accordingly, the following experiments in dogs were carried out to determine whether compliance changes in the ischemic tissue after infarction are observed.

\section{METHODS}

Studies were carried out in 27 mongrel dogs of both sexes weighing $18-30 \mathrm{~kg}$. Several types of observations were made. (a) Pressure-volume curves of the isolated postmortem ventricle in dogs with myocardial infarction due to coronary ligation, and in sham-operated animals. (b) Pressure-length curves (length measured from mercury-insilastic segment length gauges sutured to the ventricular surface) of the isolated postmortem ventricle, in preparations similar to $(a)$. (c) In situ dynamic measurements of seg- 
ment length in infarcted and noninfarcted myocardium. Measurements were also made during aortic obstruction, which raised the left ventricular end-diastolic pressure and thus provided a range of observations to evaluate in vivo pressure-length relationships. (d) In situ ventricular enddiastolic volumes measured by indicator dilution methods, in relation to the observed left ventricular end-diastolic pressure.

Postmortem pressure-volume curves of the left ventricle. These studies were carried out in 10 dogs with myocardial infarction produced by two-stage ligation of the left anterior descending coronary artery approximately $2 \mathrm{~cm}$ below its origin (12) and in six sham-operated animals, as previously described (3). These surgical procedures were carried out under $30 \mathrm{mg} / \mathrm{kg}$ pentobarbital anesthesia. Animals were reanesthetized with $30 \mathrm{mg} / \mathrm{kg}$ of pentobarbital and sacrificed in the period 3-5 days after the initial ligation or sham operation by rapid intravenous injection of a saturated solution of potassium chloride. The heart was rapidly excised, the atrioventricular ring and aortic root including the coronary ostia were sealed off using curved metal clamps, and two separate catheters were sutured into the left ventricular apex for infusion of fluid and for measurement of pressure. After exhausting the ventricle by aspirating with a syringe, lactated Ringer's solution at room temperature was infused into the ventricles at a rate of $1.6 \mathrm{ml} / \mathrm{sec}$ to a pressure of $40 \mathrm{~mm} \mathrm{Hg}$. For this procedure intraventricular pressure was measured with a Statham P23Db transducer (Fig. 1). The volume infused could always be completely recovered by withdrawal from the ventricle. Pressure was plotted against cumulative volume, for both ligated and sham-operated animals, to generate pressure-volume curves of the left ventricle (Fig. 1). This entire procedure was completed in 45 min or less to avoid postmortem compliance changes which may occur beyond this time interval in normal hearts (13), as well as in hearts with infarction. ${ }^{1}$ After the compliance study the left ventricle was excised and weighed. Volume data for the compliance curves were normalized to a ventricular weight of $100 \mathrm{~g}$.

Postmortem pressure-length curves of the left ventricle. Studies similar to the above were carried out in five animals with infarcts for measurement of pressure-length relationships. These were evaluated by suturing mercury-in-silastic segment length gauges (10) ranging from 1.5 to $3 \mathrm{~cm}$ in length transversely to the mid-anterior wall of the left ventricle. Two gauges were placed on each heart, one directly in the center of the infarcted tissue, and one several centimeters away over the lateral wall of the left ventricle where no infarct was present. Additional studies were performed in six animals without infarction by suturing a single gauge to the lateral wall of the left ventricle. Gauges were calibrated as previously described (10). Pressure-length relationships were measured in a fashion identical with pressure-volume curves, by isolating and fluid loading the left ventricle, while intraventricular pressure and segment length measurements were made.

Dynamic (in situ) segment length measurements. In three of the animals studied with postmortem pressure-length curves, observations were made in situ before sacrifice. After a second thoracotomy procedure under $30 \mathrm{mg} / \mathrm{kg}$ pentobarbital anesthesia, gauges were attached directly to the surface of the beating heart. Left ventricular pressure was also measured as previously described (10) from a catheter placed in the left ventricular apex and attached to a Statham

\footnotetext{
${ }^{1}$ Hood, W. B., Jr. Unreported data.
}

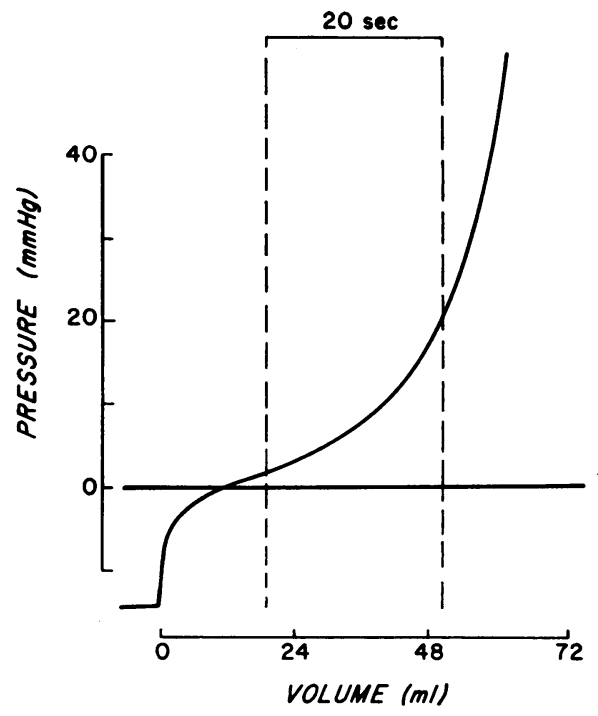

FIGURE 1 Pressure curve (redrawn) inscribed by infusing lactated Ringer's solution into the left ventricle at a constant rate of $1.6 \mathrm{ml} / \mathrm{sec}$. Weight of the left ventricle $=108 \mathrm{~g}$.

$\mathrm{P} 23 \mathrm{Db}$ gauge. After base line measurements, the ascending aorta was transiently occluded by tightening an encircling snare, so that diastolic pressures in the left ventricle became markedly elevated, thus allowing calculation of enddiastolic pressure-length curves over a range of values.

In situ pressure-volume measurements. In 12 of the animals studied with postmortem pressure-volume curves, observations were made in situ before sacrifice. Seven animals with infarcts and five sham-operated animals were studied. Ventricular volume was estimated by injecting $2.5 \mathrm{mg}$ Indocyanine Green dye in a volume of $2.0 \mathrm{cc}$ into the left ventricle through a No. 7F multiple end-hole catheter, and monitoring dye concentration in the aortic root using a No. $7 \mathrm{~F}$ fiberoptic catheter attached to a recording system with a $0.1 \mathrm{sec}$ time constant (14)..$^{2}$ An average of three curves was taken to compute end-diastolic volume. Such injections resulted in appearance of dye in the aortic root in discrete step functions (Fig. 2). Cardiac output was calculated from these same curves, and divided by heart rate to obtain stroke volume. From these relationships left ventricular end-diastolic volume could be computed (see below). Left ventricular pressures, uncorrected for intrapleural pressure, were measured using a Statham P23Db transducer.

Graphical analysis, calculations, and definitions. For postmortem pressure-length curves, normalization to the length of the ventricular segment at $10 \mathrm{~mm} \mathrm{Hg}$ pressure was carried out according to the relationship :

$$
\text { Normalized length }=\frac{\text { Observed length }}{\text { Length at } 10 \mathrm{~mm} \mathrm{Hg}}
$$

This allowed comparison of measurements using gauges of different lengths. Construction ' of pressure-length curves from data obtained in situ was performed by plotting left ventricular end-diastolic pressure against measured enddiastolic segment length, from tracings obtained during

\footnotetext{
${ }^{2}$ American Optical Corp., Reflectometer. Southbridge, Mass.
} 


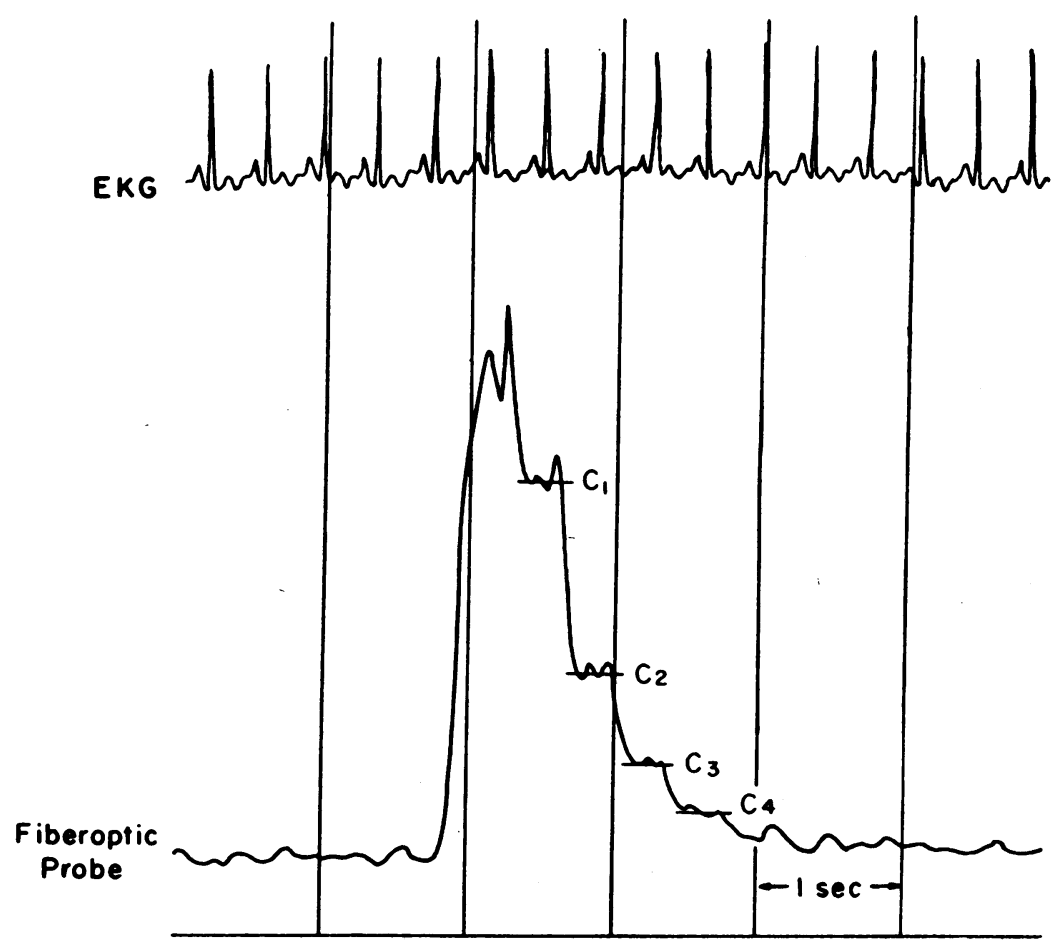

FIGURE 2 Example of indicator dilution curve inscribed by fiberoptic probe (time constant $0.1 \mathrm{sec}$ ) in aortic root, with injection of Indocyanine Green dye into the left ventricle. In this example $(\mathrm{Cn} / \mathrm{Cn}-1)$ of 0.50 was obtained as the average of $\mathrm{C} 2 / \mathrm{C} 1=0.49, \mathrm{C} 3 / \mathrm{C} 2=0.51$, and $\mathrm{C} 4 / \mathrm{C} 3=0.49$. With cardiac output of 5.8 liters/min, heart rate of 160 , and derived stroke volume of $36 \mathrm{ml}$, ventricular end-diastolic volume was calculated as :

$$
\begin{aligned}
\text { (stroke volume) } /\left[1-\left(\frac{\mathrm{Cn}}{\mathrm{Cn}-1}\right)\right] & =(36) /(1-0.50) \\
& =72 \mathrm{ml} \text { (see Methods). }
\end{aligned}
$$

aortic occlusion, while both values were steadily increasing. For both pressure-volume and pressure-length curves, the first curve obtained postmortem was analyzed since stressrelaxation was often noted when the measurements were repeated.

Calculation of ventricular diastolic volume from indicator dilution curves was carried out according to the method described by Holt (15), using the relationship:

$$
\mathrm{EDV}=\frac{\mathrm{SV}}{1-\left(\frac{\mathrm{Cn}_{n}}{\mathrm{Cn}_{n}-1}\right)}
$$

where $\mathrm{EDV}=$ end-diastolic volume, $\mathrm{SV}=$ stroke volume, and $\mathrm{Cn} / \mathrm{Cn}-1$ is the inverse ratio of successive steps along the exponential downslope of the indicator washout curve. A sample calculation is shown in Fig. 2. Statistical analyses were carried out using the $t$ test of Student (16).

Compliance is defined in this manuscript as the slope of the pressure-volume or pressure-length curve, and stiffness as the reciprocal of compliance.

\section{RESULTS}

Postmortem pressure-volume curves. Ventricles from animals with infarction were found to be less compliant than the sham-operated controls (Fig. 3), as shown by the steeper pressure-volume curves obtained in the former. The ventricular volumes in the two groups did not differ significantly at 0 or $5 \mathrm{~mm} \mathrm{Hg}$, but above this value, because of the reduced compliance among animals with infarction, showed progressive and significant divergence (Fig. 3 ).

Postmortem pressure-length curves. To determine whether this observed increase in stiffness of the entire ventricle was localized to the infarcted tissue, pressurelength measurements were made from both infarcted and normal tissue. It was noted that the areas of infarction showed a marked decrease in compliance compared to the adjacent normal tissue, and that the compliance of the latter did not differ significantly from normal myocardium in animals without infarction (Fig. 4). Thus the diminished compliance of the entire ventricle noted in the pressure-volume studies is attributable to an increase in stiffness of the infarcted muscle, and the compliance of the noninfarcted muscle remains normal. In situ measurements. Similar observations were ob- 


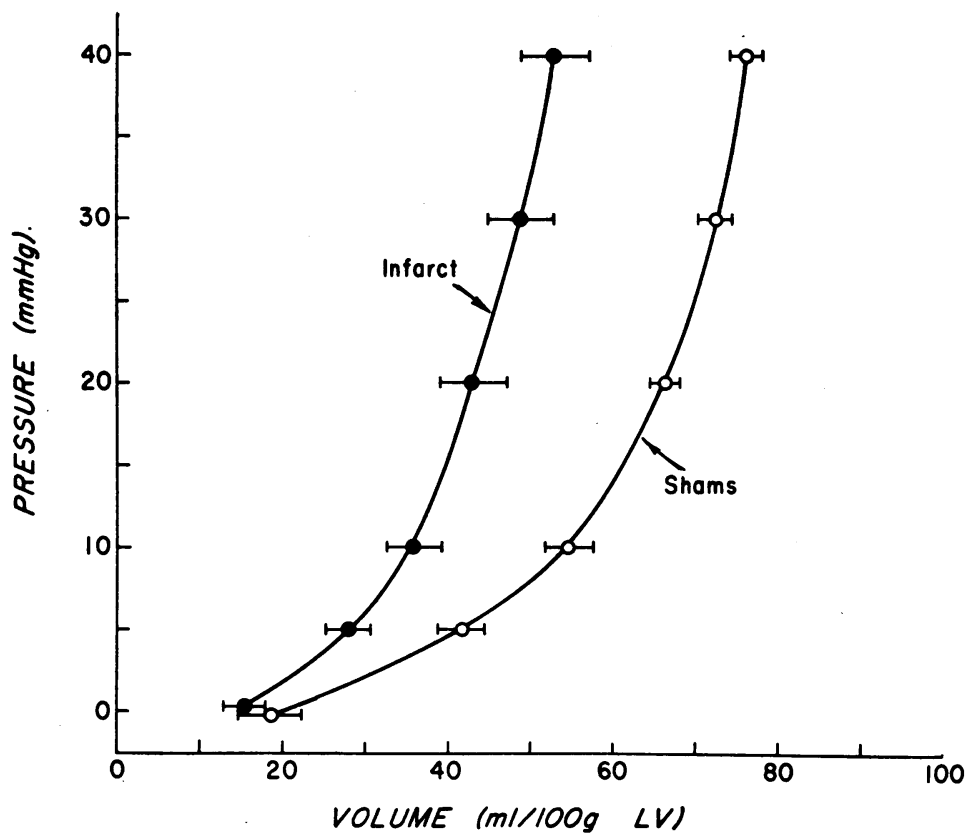

FIGURE 3 Postmortem pressure-volume curves of ventricles with and without infarction. Infarcts range in age from 3 to 5 days. Bars show SEM. At atmospheric pressure the volumes did not differ significantly, but at pressures of $10-40 \mathrm{~mm} \mathrm{Hg}$ the volumes of the infarcted ventricles were reduced compared to controls $(P<0.05)$.

tained in the open-chested animal by measurements made from the surface of the beating heart. Segment length gauge tracings made from infarcted and adjacent normal tissue showed that excursions were greatly reduced in the infarcted muscle (Fig. 5). Furthermore, when the aorta was transiently obstructed, causing marked

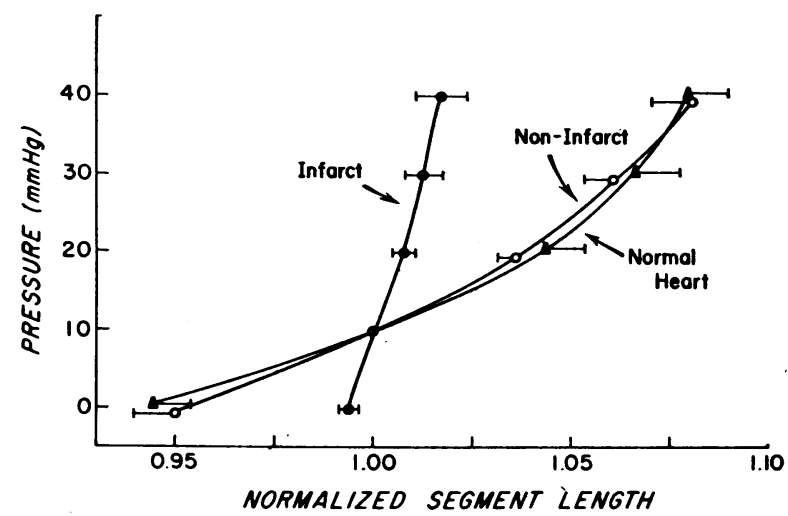

FIGURE 4 Postmortem pressure-length curves of infarcted area (closed circles) and adjacent noninfarcted area (open circles), compared with curves in normal animals (triangles). Bars show SEM. The infarcted areas show reduced length at all levels of pressure above $10 \mathrm{~mm} \mathrm{Hg}(P<0.05)$ compared to the adjacent noninfarcted areas, and to normal ventricles. Points along the latter two curves do not differ significantly. elevation of ventricular pressures, diastolic lengthening of the gauge over the infarct was much more limited than over adjacent normal myocardium (Fig. 5). A plot of left ventricular end-diastolic pressure-length curves in the three experiments is shown in Fig. 6. The curves are quite similar to those obtained in postmortem studies.

This behavior of the ischemic tissue in the recovery phase of acute myocardial infarction differs markedly from that observed immediately after the onset of ischemia, when aneurysmal bulging of the ischemic zone is uniformly noted $(9,10)$. Animals have been followed for up to $2 \mathrm{hr}$ after onset of ischemia, and no evidence of stiffening (i.e. decreased bulging) has been noted within this time period. ${ }^{1}$

In situ pressure-volume measurements. In the seven animals with coronary ligation and five with sham operations differences in left ventricular pressure-volume relationships in situ were noted (Table I). Thus although left ventricular end-diastolic volume was virtually identical in the two groups of animals, left ventricular end-diastolic pressure was significantly higher in the animals with infarcts. These findings are in agreement with the postmortem studies.

\section{DISCUSSION}

Diminished left ventricular compliance has been observed in various disease states such as aortic $(17,18)$ 

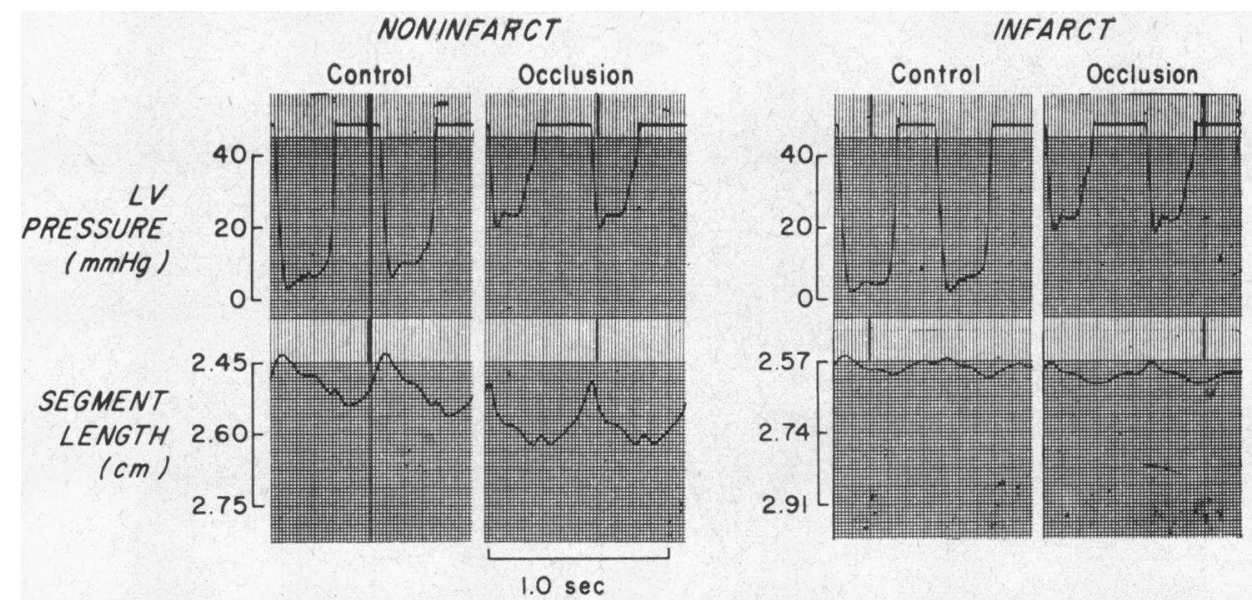

FIGURE 5 In situ pressure-length relationships in the left ventricle of an animal with infarction. Left: pressure measurements and segment length measurements in the non-infarcted area, before and after elevation of left ventricular end-diastolic pressure by transient aortic occlusion. Right: similar measurements with segment length tracings made from adjacent infarcted myocardium.

and subaortic $(19,20)$ stenosis. In both of these disorders elevated left ventricular end-diastolic pressures were associated with normal or near-normal ventricular end-diastolic volumes. In the case of subaortic stenosis, ventricular end-diastolic volume may even be low. These changes in compliance are thought to be due to thickening and hypertrophy of the left ventricular wall, preventing normal expansion and ventricular filling at physiologic diastolic pressures $(19,20)$.

Decreased ventricular compliance and localization of this decrease in compliance to the infarcted muscle have

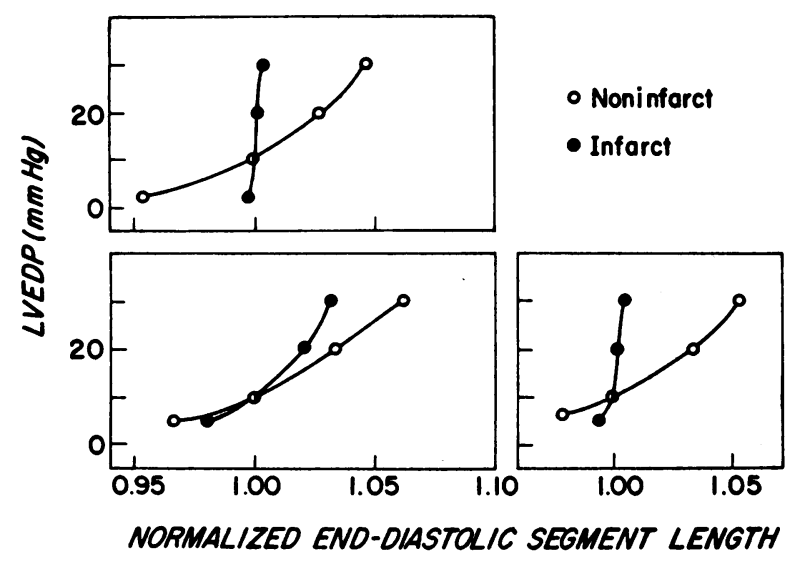

FIgURE 6 Pressure-length measurements obtained in situ during transient aortic occlusion in three experiments (see Fig. 5). Graphs obtained by plotting left ventricular enddiastolic pressure (LVEDP) vs. end-diastolic segment length in the infarcted (closed circles) and adjacent normal tissue (open circles). not heretofore been identified as a characteristic of the early healing phase of myocardial infarction. Ventricular aneurysm as a pathological entity has been described in detail, but this is usually noted to be a thinned out and dilated scarred area of myocardium (21), without specific information about the actual elasticity of the walls of the aneurysm or pressure-volume relationships of the ventricle. On occasion in patients with ventricular aneurysm the ventricular volume may be normal or nearly so despite elevated left ventricular end-diastolic pressure (22). In addition ventriculograms in such patients often show immobility or absence of motion rather than aneurysmal bulging during systole, suggesting that the ventricular wall may be relatively stiff and inelastic (22). However most of these clinical observations have been made in patients with chronic ischemic lesions, and may not be applicable to the early healing phase of myocardial infarction considered in the present investigation.

The pathological changes observed in canine myocardial infarction in the 3-5 day postinfarct time period examined here have been described in detail. They consist of central necrosis, edema, and polymorphonuclear leukocytic infiltration in the infarct, and formation of granulation tissue with new growth of vessels and fibroblasts around the margins (23). This picture differs from that observed in later stages of healing, when fibrous tissue ingrowth and collagen formation become prominent.

Few physiologic studies are available in animals. In one study, carried out several weeks after coronary constriction, diminished compliance of ischemic muscle was suggested by the finding that diastolic tension, mea- 
TABLE I

In Situ End-Diastolic Pressure-Volume Measurements

\begin{tabular}{|c|c|c|c|c|}
\hline & \multicolumn{2}{|c|}{$\begin{array}{l}\text { LV end-diastolic } \\
\text { pressure }\end{array}$} & \multicolumn{2}{|c|}{$\begin{array}{l}\text { LV end-diastolic } \\
\text { volume }\end{array}$} \\
\hline & Sham & Ligated & Sham & Ligated \\
\hline & \multicolumn{2}{|c|}{$m m \mathrm{Hg}$} & \multicolumn{2}{|c|}{$m l / 100 \mathrm{~g} \mathrm{LV}$} \\
\hline Mean & 2.9 & 7.9 & 78 & 79 \\
\hline SEM & 1.2 & 1.0 & 11 & 10 \\
\hline Significance & \multicolumn{2}{|c|}{$0.01<P<0.02$} & \multicolumn{2}{|c|}{ NS } \\
\hline
\end{tabular}

sured with a strain gauge arch, was higher in ischemic compared with normal muscle when the muscle was stretched (24). However this was present only during unphysiologic stretching of the myocardium to greater than $25 \%$ of resting length (24), whereas this difference was not apparent in the physiologic range of up to $10 \%$ stretch (pressure range $0-40 \mathrm{~mm} \mathrm{Hg}$ ), as in the present study (Figs. 4-6). This discrepancy may be due to certain errors inherent in the use of the strain gauge arch, since lengthening of the arch in the physiologic range of stretch may have merely straightened out the curvature of the underlying muscle, without developing tension. It may also be that the degree of ischemia and damage to the injured muscle was less in that study than in the present one, since slowly occluding ameroid constrictors rather than direct ligations were employed to produce ischemia (24). Another study has been performed which analyzed "active stiffness" of the left ventricle following experimental canine myocardial infarction (25). "Active stiffness" is the calculated series elastic stiffness for the whole left ventricle, and as such, deals only with events during systole. It is not a measure of diastolic compliance. Calculated "active stiffness" would, however, be expected to decrease in the presence of aneurysmal bulging in systole, and to increase if the aneurysm disappeared. The results of the present study would be compatible with the finding of a decline in active stiffness immediately after infarction, followed by a rise during the healing phase. That this was not the case in the study quoted (25) remains unexplained, but might be due to the relatively small size of the infarcts produced.

In the present study the method used to obtain postmortem pressure-volume curves gives values which are smaller than those obtained by angiographic techniques (26), probably due to restriction of ventricular dimensions by cross-clamping the mitral valve. Likewise the indicator dilution method for obtaining in vivo ventricular volume may systematically yield larger volumes than those which actually exist (27). However it is unlikely that the error of either technique would alter the conclusions of the present study, since comparisons between control and coronary ligated groups would be influenced to a similar degree.

From the present experiments it is clear that the area of damage in experimental canine myocardial infarction becomes relatively stiff and inelastic within the first 5 days after infarction. The experiments show that a significant decrease in over-all postmortem ventricular compliance occurs during the healing phase of experimental myocardial infarction (Fig. 3), and that this increase in stiffness is localized to the site of the infarct both at postmortem (Fig. 4) and in situ (Figs. 5 and 6). That this change in compliance does not occur at the onset of infarction is indicated by results of acute experiments, which uniformly show aneurysmal bulging $(9,10)$. Hence the alterations occur sometime during the first few days after onset of ischemia.

It should also be noted that the stiffening which occurs in the infarct in effect represents a "contracture." At pressures exceeding $5 \mathrm{~mm} \mathrm{Hg}$ there appears to be segmental shortening in the area of infarction, compared to normal myocardium. This conclusion follows from the finding of a reduced ventricular volume (Fig. 3 ), in the presence of normal compliance in noninfarcted muscle (Fig. 4). Restriction of volume in the infarcted ventricles is due solely to the increased stiffness of the infarcted zone. Thus, in the presence of elevated filling pressures, the relative segmental shortening of the infarcted zone represents a state of "contracture," or drawing in of the margins of the infarct.

These findings have implications regarding the function of normal noninfarcted myocardium adjacent to the area of damage. Since the passive length-tension curve of the noninfarcted muscle does remain normal (Fig. 4), presumably the Frank-Starling mechanism continues to operate in this portion of the myocardium in the normal way. Under these circumstances left ventricular enddiastolic pressure should be a better indicator of the degree to which these normal fibers are stretched during diastole than actual measurements of ventricular volume.

It is also possible that function of the noninfarcted area of myocardium is altered by other mechanisms, such as hypertrophy (28). In fact it has been suggested that noninfarcted fibers in experimental infarction may show increased shortening, compared to normal hearts (29). Metabolic changes in noninfarcted myocardium have also been demonstrated (30).

It should be noted that an increase in stiffness of the infarcted zone of myocardium would contribute to improvement of over-all left ventricular performance in the healing phase of acute myocardial infarction. Improvement in left ventricular function has been demonstrated in experimentally implanted left ventricular aneurysm when the aneurysm was either clamped off or 
replaced with a stiff patch $(31,32)$, or when aneurysms induced by coronary ligation were excised (33). Spontaneous disappearance of aneurysmal bulging during systole noted in the present study would presumably also lead to diminished sequestration of blood, and improved ejection fraction and stroke volume. Improvement of ventricular function with serial hemodynamic measurements has been demonstrated in experimental canine myocardial infarction (11), and in some instances of clinical myocardial infarction (5-8). The results of the present study provide a definitive mechanism for explaining these findings, though quantitative evaluation of the contribution to effective stroke volume which stiffening of the infarcted zone may provide remains to be defined.

\section{ACKNOWLEDGMENTS}

We wish to thank Mrs. Faye M. Alpert for secretarial assistance. We are grateful to Hynson, Westcott \& Dunning, Inc., Baltimore, Md., for the Indocyanine Green dye used in these experiments.

This work was supported by Grants PH 43-68-684, HE 10539, HE 5244, HE-07776-04, and 5TI-HE-5242 from the National Heart Institute, the Ernest W. Lawson Grant, Northeast Chapter, Massachusetts Heart Association, and by the John A. Hartford Foundation.

\section{REFERENCES}

1. Case, R. B., E. Berglund, and S. J. Sarnoff. 1954. Ventricular function. II. Quantitative relationship between coronary flow and ventricular function with observations on unilateral failure. Circ. Res. 2: 319.

2. Stone, H. L., V. S. Bishop, and A. C. Guyton. 1963. Cardiac function after embolization of coronaries with microspheres. Amer. J. Physiol. 204: 16.

3. Hood, W. B., Jr., B. McCarthy, and B. Lown. 1967. Myocardial infarction following coronary ligation in dogs. Hemodynamic effects of isoproterenol and acetylstrophanthidin. Circ. Res. 21: 191.

4. Hood, W. B., Jr., B. McCarthy, and B. Lown. 1969. Aortic pressure loading in dogs with myocardial infarction. Amer. Heart J. 77: 55.

5. Gammill, J. F., J. J. Applegarth, C. E. Reed, J. D. Fernald, and A. J. Antenucci. 1955. Hemodynamic changes following acute myocardial infarction using the dye injection method for cardiac output determination. Ann. Intern. Med. 43: 100.

6. Lee, G. de J. 1957. Total and peripheral blood flow in acute myocardial infarction. Brit. Heart J. 19: 117.

7. Broch, O. J., S. Humerfelt, J. Haarstad, and J. R. Myhre. 1959. Hemodynamic studies in acute myocardial infarction. Amer. Heart J. 57: 522.

8. Murphy, G. W., G. Glick, B. F. Schreiner, Jr., and P. N. $\mathrm{Yu}$. 1963. Cardiac output in acute myocardial infarction. Serial determinations by precordial radioisotope dilution curves. Amer. J. Cardiol. 11: 587.

9. Tennant, R., and C. J. Wiggers. 1935. The effect of coronary occlusion on myocardial contraction. Amer. J. Physiol. 112: 351.
10. Hood, W. B., Jr., V. H. Covelli, W. H. Abelmann, and J. C. Norman. 1969. Persistence of contractile behaviour in acutely ischaemic myocardium. Cardiovasc. Res. 3: 249.

11. Kumar, R., W. B. Hood, Jr., J. Joison, J. C. Norman, and W. H. Abelmann. 1970. Experimental myocardial infarction. II. Acute depression and subsequent recovery of left ventricular function: serial measurements in intact conscious dogs. J. Clin. Invest. 49: 55 .

12. Harris, A. S. 1950. Delayed development of ventricular ectopic rhythms following experimental coronary occlusion. Circulation. 1: 1318.

13. Laks, M. M., D. Garner, and H. J. C. Swan. 1967. Volumes and compliances measured simultaneously in the right and left ventricles of the dog. Circ. Res. 20: 565.

14. McCarthy, B., W. B. Hood, Jr., and B. Lown. 1967. Fiberoptic monitoring of cardiac output and hepatic dye clearance in dogs. J. Appl. Physiol. 23: 641.

15. Holt, J. P. 1956. Estimation of the residual volume of the ventricle of the dog's heart by two indicator dilution technics. Circ. Res. 4: 187.

16. Fisher, R. A. 1958. Statistical Methods for Research Workers. Hafner Publishing Company Inc., New York. 13th edition. 174.

17. Dodge, H. T., R. E. Hay, and H. Sandler. 1962. Pressure-volume characteristics of the disastolic left ventricle of man with heart disease. Amer. Heart J. 64: 503.

18. Gorlin, R., E. L. Rolett, P. M. Yurchak, and W. C. Elliott. 1964. Left ventricular volume in man measured by thermodilution. J. Clin. Invest. 43: 1203.

19. Greenwood, W. F., H. E. Aldridge, and E. D. Wigle. 1965. The nature of the disorder of function in chronic postinfarction aneurysm of the left ventricle. Can. Med. Ass. J. 92: 611.

20. Lewis, R. P., J. D. Bristow, C. Farrehi, F. E. Kloster, and H. E. Griswold. 1965. Idiopathic left ventricular hypertrophy: a hemodynamic reappraisal. Amer. J. Med. 38: 842 .

21. Schlichter, J., H. K. Hellerstein, and L. N. Katz. 1954. Aneurysm of the heart: a correlative study of one hundred and two proved cases. Medicine. 33: 43.

22. Klein, M. D., M. V. Herman, and R. Gorlin. 1967. A hemodynamic study of left ventricular aneurysm. Circulation. 35: 614 .

23. Tennant, R., D. M. Grayzel, F. A. Sutherland, and S. W. Stringer. 1936. Studies on experimental coronary occlusion. Chemical and anatomical changes in the myocardium after coronary ligation. Amer. Heart J. 12: 168.

24. Nakhjavan, F. K., R. Son, and H. Goldberg. 1968. Myocardial contractility in areas with chronic ischaemia : studies on isometric tension. Cardiovasc. Res. 2: 226.

25. Forwand, S. A., K. M. McIntyre, J. G. Lipana, and H. J. Levine. 1966. Active stiffness of the intact canine left ventricle. With observations on the effect of acute and chronic myocardial infarction. Circ. Res. 19: 970.

26. Mullins, C. B., D. C. Jones, and J. H. Mitchell. 1969. Comparison of left ventricular volume by the biplane cineangiographic method and the pressure-volume curve method. Clin. Res. $17: 256$. (Abstr.)

27. Carleton, R. A., A. F. Bowyer, and J. S. Graettinger. 1966. Overestimation of left ventricular volume by the indicator dilution technique. Circ. Res. 18: 248. 
28. Bergmann, W. 1968. Der Bindegewebsgehalt im Herzmuskel des Menschen bei akutem und chronischem Myokardinfarkt. Archiv für Kreislaufforschung 56: 106.

29. Hood, W. B., Jr. 1970. Experimental myocardial infarction. III. Recovery of left ventricular function in the healing phase: contribution of increased fiber shortening in non-infarcted myocardium. Amer. Heart J. 79: 531.

30. Gudbjarnason, S., and P. S. Puri. 1969. Adenine-nucleotide levels of non-ischemic cardiac muscle following coronary occlusion. Fed. Proc. 28: 452.
31. Tyson, K., I. Mandelbaum, and H. B. Shumacker, Jr. 1962. Experimental production and study of left ventricular aneurysms. J. Thorac. Cardiovasc. Surg. 44: 731.

32. Austen, W. G., T. Tsunekawa, H. W. Bender, P. A. Ebert, and A. G. Morrow. 1962. The acute hemodynamic effects of left ventricular aneurysm: an experimental study in dogs J. Surg. Res. 2: 161.

33. Heimbecker, R. O., C. Chen, N. Hamilton, and D. W. G. Murray. 1967. Surgery for massive myocardial infarction. An experimental study of emergency infarctectomy. Surgery. $61: 51$. 